\begin{tabular}{l|l} 
REVISTA & $\begin{array}{l}\text { Revista Educación } \\
\text { ISSN: 0379-7082 } \\
\text { ISSN: 2215-2644 } \\
\text { revedu@ gmail.com } \\
\text { Universidad de Costa Rica } \\
\text { Costa Rica }\end{array}$
\end{tabular}

\title{
El reto de la identidad para la educación como institución social
}

Matías González, Alberto; Hernández del Cristo, Shirley Bárbara

El reto de la identidad para la educación como institución social

Revista Educación, vol. 42, núm. 2, 2018

Universidad de Costa Rica, Costa Rica

Disponible en: http://www.redalyc.org/articulo.oa?id=44055139006

DOI: https://doi.org/10.15517/revedu.v42i2.23598

Esta obra está bajo una Licencia Creative Commons Atribución-NoComercial-SinDerivar 3.0 Internacional. 


\title{
El reto de la identidad para la educación como institución social
}

\section{Identity challenges for education as a social institution}

Alberto Matias González [1]

Universidad de Santi Spiritus José Martí Pérez, Cuba

albertomg1122@gmail.com

Shirley Bárbara Hernández del Cristo [2]

Universidad de Santi Spiritus José Martí Pérez, Cuba

shirley@uniss.edu.cu

\author{
DOI: https://doi.org/10.15517/revedu.v42i2.23598 \\ Redalyc: http://www.redalyc.org/articulo.oa?id=44055139006
}

Recepción: 23 Marzo 2016

Aprobación: 20 Marzo 2018

\section{Resumen:}

La realización y construcción social de la identidad humana es una permanente convocatoria para repensar su ejercicio y significado. El presente ensayo participa de este empeño y su objetivo es lograr una aproximación teórica al sentido e influencia de la construcción del valor identidad para la educación en condiciones de lucha por la igualdad social. El aporte radica en una visión fundamentada en torno al lugar de la educación en el despliegue de relación identidad/diferencia y asume que la búsqueda de la igualdad social es fundamental para ello. Las nociones reflexivas fueron elaboradas desde las realidades de los países en desarrollo, realidades que están insertadas en un siglo en que el mundo se revoluciona en el campo de las tecnologías y donde, por otra parte, florecen las intolerancias y fundamentalismos sociales. La conclusión fundamental a que se llega es que la búsqueda de la igualdad en la diferencia debe ser prioridad para la construcción social de la identidad y, en ello, juega un papel central la educación.

Palabras Clave: Identidad, valores, educación, igualdad, diversidad.

\section{Abstract:}

The fulfillment and social construction of the human identity is a permanent call to think it over in terms of practice and meaning. The present essay belongs to this kind of efforts. The objective of this research is to achieve a theoretical approach to the meaning and influence of the identity construction value, under fighting conditions, for social equality. This contribution lies on a grounded vision about education in an identity/difference relationship assuming that the search for social equality is fundamental. The notions were elaborated based on reflections made from the realities of all developing countries, in a century where the world faces a revolution in the field of technology while intolerance and social fundamentalism arise. The main conclusion is that the search for equality in the difference should be a priority for the social construction of identity and where education plays a key role.

KEYWORDS: identity, values, education, equality, diversity.

\section{Notas DE AUTOR}

[1] Doctor en Gestión Ambiental y Desarrollo Sostenible por la Universidad de Girona, España, título que homologó en Cuba como Doctor en Sociología. Profesor titular de la Universidad de Sancti Spíritus, José Martí Pérez, en Cuba. Master en Ciencia, Tecnología y Sociedad, por la Universidad de la Habana. Licenciado en Educación con especialidad en Historia y marxismo. Ha impartido las asignaturas de Filosofía, Pensamiento filosófico y social contemporáneo, Filosofía de la educación y Problemas sociales de la ciencia y la tecnología. Es investigador del Centro de Estudios de Educación Superior de la referida Universidad, donde participa en varios proyectos de investigación, en áreas referidas a filosofia de la educación. Como resultado de esta actividad ha publicado diversos trabajos y participado en varios congresos. En la actualidad está incorporado al Programa Nacional de Pos-doctorado de la CAPES-Brasil, con bolsa de esa institución, vinculado al Programa de Pos-graduación en Educación de la Universidad de Uberaba (UNIUBE), MG, Brasil.

[2] Licenciada en Comunicación Social, con una Especialidad de Postgrado en Trabajo Social. Profesora asistente de la Universidad de Sancti Spíritus José Martí Pérez, en la cual imparte la asignatura de Filosofía, con cuatro años de experiencia, participa además en un proyecto de investigación referido a la noción de identidad. 


\section{INTRODUCCIÓN}

El discurso ideológico actual es un polémico escenario que inserta entre sus inquietudes la problemática de la identidad humana: ¿Cómo participar de su construcción social en medio de procesos de globalización? ¿Qué hacer para defenderla, reformarla, enmendarla o afirmarla? ¿Qué escala de preferencia en valores deben conformarla? Estas son interrogantes que matizan una multiplicidad de inquietudes y que, aunque han sido un tema suscrito en las preocupaciones teóricas desde los mismos orígenes del pensamiento social, no hay dudas de su relevancia creciente en las últimas décadas.

La identidad es un hecho vivencial y experimental, que siempre ha tenido una diversidad configurativa que se realiza a través de procesos de interinfluencias, donde intervienen numerosos factores, principalmente de orden social, biológico y geográfico. En medio de estas interinfluencias se despliegan las necesidades, intereses, preferencias, inquietudes, anhelos, voluntades y deseos de los seres humanos. Su existencia se complementa a través de la diferencia.

Como la identidad humana se construye socialmente y es un componente participe del ejercicio de las estructuras ideológicas e institucionales, las formas organizativas de la sociedad crean entidades, mecanismos y políticas para su gestión y desarrollo en una u otra dirección. Ha sido y sigue siendo la educación uno de los espacios que, aunque se lo proponga o no de manera consciente, siempre participa del proceso que construye, elige, diseña, reproduce y promueve la identidad; lo más común se aprecia en la incorporación de programas de historia a los currículos escolares o en el diseño y ejecución de actividades culturales dedicadas a manifestaciones artísticas tradicionales.

Este ensayo tiene como objetivo lograr una aproximación teórica al significado de la educación para el proceso de la construcción social de la identidad, en condiciones de un mundo que se globaliza, por supuesto, en su nexo con la diferencia, pues esta constituye una realidad complementaria y contradictoria de la identidad. Para ello, las personas autoras destacan solo aquellas implicaciones que consideran más relevantes. El trabajo se ha estructurado en tres epígrafes, el primero reflexiona sobre las determinaciones conceptuales; el segundo aborda cuestiones generales acerca del papel que debe jugar la educación en la configuración de la identidad y, el tercero está dirigido a valorar las importancia que tiene la educación en la formación de la igualdad social y su valor para construir la identidad.

Asumir hoy, desde la educación, el proceso de construcción social de la identidad como ejercicio responsable, sistemático y con la seriedad requerida, es un acto de genuina defensa ante el acoso de los ídolos que marcan el mundo globalizado: Hollywood, Walt Disney, McDonald's, marcas comerciales, signos, programas televisivos fuertemente comprometidos con fórmulas de recolonización; todo diseñado generalmente en los países desarrollados de occidente y dispuesto para borrar el espíritu de identificación de los pueblos con su existencia real histórica y, con ello, masificar una conciencia apática y enajenada. De ahí la importancia de debatir y socializar ideas sobre el tema.

\section{CONCEPCIONES TEÓRICAS SOBRE LA IDENTIDAD}

Preocupaciones por la identidad han existido desde siempre, pueden encontrarse alusiones a ello en los textos de filosofía, historia y literatura de sociedades antiguas, ya en la poesía épica de Homero hay evidencias de ello. Otros autores más próximos y ligados al mundo moderno, como Hegel (2003), le dieron una gran relevancia y lo convirtieron en un tema central de sus reflexiones dialécticas.

En las últimas décadas el análisis de la identidad ha sido objeto de atención del pensamiento social con sus consiguientes desarrollos teóricos. Textos como los de Ricoeur (2004), Giddens (1997) y Taylor (2006) abordan la existencia de la identidad en la diferencia y en sus dimensiones histórico-culturales y sociológicas, otros (Dussel, 2006; Mignolo, 2008; Sousa, 2010) argumentan la necesidad de reconstruir la identidad como arma de descolonización de la cultura y del pensamiento. Para el pensamiento pedagógico y educativo la 
cuestión también es recurrente, se destaca la idea de vincular la educación popular con una perspectiva de identidad que legitime la construcción de un sujeto social emancipador, el caso de Freire (2002) es ilustrativo en ese empeño.

Desde la teoría, la formación de la identidad puede ser entendida como un proceso de síntesis, que se desarrolla a partir de la influencia que en los individuos o en las comunidades humanas genera la dinámica de lo diverso; diversidad que al mismo tiempo es expresión de las complejas estructuras de agrupación y significado en que participan las personas. Así, una misma persona puede sentir pertenencia a una familia, un género, una ciudad, una nación, una o varias religiones, un partido político; la lista sería interminable (Maalouf, 1999), caben tantas posibilidades como formas distintas de agruparse y de sentir asumen las personas.

Visto desde una noción de proceso, se puede entender la identidad como un ejercicio en movimiento que se va diferenciando de sí misma en su interacción con el otro, con lo diferente del cual asimila y rechaza, enriquece y empobrece; asumiendo actitudes de conciliación o exclusión (Maalouf, 1999), en una relación, no tanto de dicotomías absolutas, sino más bien de complementariedad.

La identidad humana engloba un componente cultural y contiene además de los factores sociales de la cultura, elementos biológicos y geográficos; por ello resulta necesario establecer las bases epistemológicas a partir de las cuales se asume el concepto de cultura. La palabra cultura procede del verbo latino colo, colis, colere y significa en principio cultivar la tierra (Ariño, 1997).

El término cultura en la literatura y en las representaciones populares presenta una pluralidad de usos y significados; de modo general se ha utilizado para: designar instituciones dedicadas a la promoción de las artes y el conocimiento, referirse a la civilización o designar los modos de existir, crear y pensar de diversos grupos humanos y personas. Es importante subrayar que esta diversidad semántica es evidencia de una dinámica que muestra una noción de movimiento del término, así como del interés que el mundo académico ha manifestado por el tema.

Uno de los primeros referentes de comprensión de la cultura lo encontramos en la obra del antropólogo inglés Tylor (1975):

La cultura o civilización, en sentido etnográfico amplio, es ese todo complejo que incluye el conocimiento, las creencias, el arte, la moral, el derecho, las costumbres y cualesquiera otros hábitos y capacidades adquiridos por el hombre en cuanto miembro de una sociedad. (p. 29)

Como se aprecia, esta definición de Tylor (1975) expresa una noción de totalidad compleja que, independientemente del tiempo que hace de su formulación, es actual e imprescindible para cualquier análisis.

Otro aporte significativo puede ser localizado en la obra de Malinowski (1984), quien exploró sus componentes materiales al insistir en los nexos de la cultura con las necesidades naturales, así como en sus estructuras institucionales a través de las cuales las comunidades canalizan actividades y tareas vitales de los grupos a que se incorporan.

También, y asumiendo un enfoque estructuralistas, Lévi-Strauss (1995) insistió en la influencia de factores lingüísticos, y favoreció el interés por los signos de la vida social y sus componentes estructurales.

Las autorías no pretenden construir una síntesis teórica de la evolución de la noción de cultura, pues la lista de quienes tratan el tema es muy amplia y se parte, además, de la consideración de que en los tres autores citados encontramos los fundamentos epistémicos de la cultura asumidos como elementos para entender la identidad humana y que se concretan en lo siguiente:

- Totalidad sistémica de creencias, normas, valores, hábitos, conocimientos, contradicciones y relaciones, así como de la herencia histórica recibida.

- Capacidades de aprendizaje y de transmisión y socialización de lo aprendido.

- Existencia de signos y símbolos de la vida social. 
- Formas organizativas y de institucionalización social.

- Bases naturales de la existencia humana.

Esta noción de cultura permite entender la identidad humana como proceso histórico que encuentra la posibilidad de su reafirmación a través de la utilización de la memoria pasada, en una especie de búsqueda para legitimar realidades presentes y futuras.

Todo ser humano, toda colectividad debe dirigir su vida en una circulación interminable entre su pasado donde encuentra su identidad, apegándose a sus ascendentes y su presente donde afirma sus necesidades y un futuro hacia donde proyecta sus aspiraciones y sus esfuerzos. (Morin, 1999, p. 41)

Esto hace de la identidad una invención permanente que conjuga lo individual y lo colectivo, y donde convergen la historia, la política, el arte, las creencias morales, la educación, las teorías científicas, así como la actividad productiva de los seres humanos en su medio ambiente.

Las antinomias contenidas en el ejercicio de la identidad se derivan de su existir, en la diferencia y a través de esta, "la identidad no es diferente de modo extrínseco, sino que, en ella misma, y en su naturaleza está el ser diferente" (Hegel, 1982, p. 181). La identidad es, por ello, moviente en sí misma.

La identidad de un individuo o grupo social existe mientras quienes la ejercen se reconocen como diferentes; esta siempre participa de una dinámica muy ligada a los escenarios donde se desarrolla, incluso puede desaparecer o mutar hacia otras identidades por las influencias de los diversos acontecimientos sociales (Maalouf, 1999). Por ello, la identidad existe como proceso de conformación y fragmentación, estabilización y desestabilización, continuidad y ruptura, construcción y desconstrucción.

En la actualidad, estos sistemas de interacción social se hacen más complejos por la influencia de las transformaciones originadas por la globalización y el desarrollo de las redes y movimientos sociales, que están estrechamente ligados a la tecnología digital y a los medios de comunicación (Lipovetsky, 2000). A estas circunstancias, se une una sociedad que produce, vende y consume mucha mediocridad cultural, que propicia la idiotización del ser humano, la adicción a las drogas, los videojuegos y la exageración del erotismo como propuesta conductual.

Se desarrolla, entonces, un nuevo escenario productor de grupos y estructuras con fragmentaciones incluidas a lo interno, que difieren de las existentes hasta mediados del siglo XX; y aunque el pasado tiene presencia, esta realidad descrita en el párrafo anterior promueve identidades híbridas o reformadas con características propias e innovaciones inéditas.

Estas realidades asociadas a los nuevos entornos obligan a entender la necesidad de participar de la construcción de la identidad en los espacios educativos de manera consciente, propiciando un desempeño que valorice el lugar diferencia (Adorno, 2005).

Articular la construcción dialéctica de la identidad/diferencia exige, además, reinventar sus nociones fundantes, de modo que asumiendo una perspectiva teórica problémica se puedan cubrir las necesidades de nuevos argumentos y conceptos explicativos que sean capaces de ayudar a la formación de políticas para la educación.

La dialéctica de transición, relación viva, contradicción de la identidad/diferencia, percibida desde lo mejor del pensamiento humanista, se conecta a través del valor de la igualdad (Sousa, 2010); categoría expresada en el derecho como componente de la libertad universal, que al mismo tiempo es afirmación y continuación de los ideales instituidos desde la Revolución Francesa.

La igualdad como propósito representa una brújula para la búsqueda del necesario equilibrio de lo social, "Tenemos el derecho de ser iguales cuando la diferencia nos inferioriza y el derecho de ser diferentes cuando la igualdad pone en peligro nuestra identidad" (Sousa, 2010, p. 87). (Esta observación ocupa un lugar esencial en el segundo apartado). 
Absolutizar los límites de la identidad es un camino directo al desarrollo de antivalores representados a través de la intolerancia y la ortodoxia. Esto ocurre cuando la identidad es esgrimida para legitimar intereses hegemónicos de dominación política, económica o cultural.

Las variantes de fundamentalismo religioso que proliferan hoy en diversas regiones, nacionalismos como el fascismo de la Alemania Hitleriana, algunas versiones del sionismo o muchos de los argumentos que llevaron recientemente a Donald Trump a la presidencia de los EE. UU son ejemplos fehacientes de cómo la identidad puede ser distorsionada en detrimento y perjuicio del existir del otro ser.

$\mathrm{Al}$ absolutizar la diferencia se presenta al otro ser, como el enemigo y, con ello, se olvida que todos los seres humanos son integrantes de una única sociedad (Etzioni, 1999).

Por otra parte, los antivalores, en otra dirección, pueden jugar un papel destructor, en la medida en que participen del deterioro del entorno social o natural de su funcionamiento y existencia. Por citar un ejemplo, la identificación de programas docentes con la enseñanza tradicional de influencia neoliberal limita la formación de ideales humanistas en el alumnado, pues en ellos se les da preferencia a los conocimientos técnicos y de ciencias naturales o exactas, en este escenario la figura del personal especialista (Núñez, 1999), que sabe mucho de poco y poco de mucho, se convierte en dominante, factor este que contribuye a la formación de profesionales con horizontes cognitivos muy reducidos y de conocimientos segmentados.

Desde este marco conceptual de partida es posible reconocer la identidad como un proceso de autodescubrimiento y autoexploración crítica de las prácticas educativas, lo cual permite propiciar la incorporación de dimensiones éticas de análisis y estimular la inclusión de lo social al desempeño educativo, en especial en el proceso de enseñanza.

Por lo tanto, su ejercicio responsable contiene pensamiento crítico, como herramienta necesaria para superar el consciente o inconsciente autoengaño, individual o colectivo, de todas las formas de ortodoxia fanática. Autoengaño responsable de las manifestaciones de intolerancia social de personas, etnias y naciones, contra otros grupos humanos y con la naturaleza misma (Etzioni, 1999).

En el escenario actual, donde se construyen y reconstruyen identidades, desde la influencia de procesos globalizadores, le corresponde a la educación como institución social un encargo de relevancia.

\section{LA IDENTIDAD Y LA EDUCACIÓN}

Contribuir a la formación de una ciudadanía que se reconozca a sí misma y su cultura, y que al mismo tiempo aprenda a respetar la identidad del otro grupo es, entonces, una tarea evidente de la educación.

En las condiciones actuales, caracterizadas por el deterioro de los discursos tradicionales, la crisis de la familia, el crecimiento de la apatía política, el relativismo ético, el acoso consumista en que se ven envueltas las personas y la permanente simulación para ocultar la identidad o enmascarada en lo virtual y mediático, responder a interrogantes como: ¿cómo educar en el quién soy a partir de dónde venimos?, ¿cómo educar en el respeto al otro?, es bien difícil; mucho más, si tenemos en cuenta que ese acto de educar debe ser productor de empatía y esperanzador.

La identidad humana está estrechamente ligada al proceso de socialización, condición que encuentra en la acción creativa a través del trabajo, su expresión fundamental. El trabajo hizo al ser humano y el ser humano hizo el trabajo (Engels, 1980), en una re-ligazón evolutiva e histórica, donde participan componentes naturales que también se rehacen constantemente.

El trabajo, además de producir bienes, tiene un componente formativo que siempre está involucrado en un medio social y natural determinado. Aquí radica el fundamento epistemológico básico para entender el lugar de la educación en la construcción social de la identidad, pues el individuo, o las diversas comunidades históricas de que participa, se realizan como naturalezas sociales a través de procesos socioeducativos: la sociedad en la medida en que produce se reproduce a sí misma (Marx, 1986). 
Para la educación actual, participar del proceso de construcción de la identidad en una dialéctica con la diferencia es algo muy complejo, pero al mismo tiempo ineludible. Se necesitan nuevas teorías que ayuden a explicar y orientar ante tanta confusión y diversidad de actuaciones, que se realizan en escenarios sociales inéditos y muchas veces inesperados. Por supuesto, no se puede esperar a tener explicaciones definitivas, se trata de explorar y experimentar caminos, pero indudablemente existe un vacío teórico en la pedagogía y en la didáctica.

El ser un proceso socialmente necesario obliga a las estructuras institucionales de la educación a redefinir sistemáticamente las políticas para la protección y fomento del binomio identidad/diferencia. Como la educación se desarrolla en contextos sociales, donde intervienen, además, intereses socio-clasistas, la labor se torna también en un proceso ideológico, que nunca va a ser neutral y es menos neutral, cuanto más neutral dice ser. En verdad se está ante un proceso marcado por las líneas directrices y los objetivos a lograr por los grupos que instituyen su hegemonía.

Sin embargo, aunque la identidad tiene uno de sus orígenes en los programas promocionados por las instituciones educativas, estos solo son efectivos, si los actores sociales los interiorizan y construyen su sentido (Giddens, 1997). Por otra parte, como la identidad y el respeto a la diferencia no pueden ser dados o inculcados, la labor de los centros docentes radica en participar de su forja, de su construcción social, de su socialización, a través de acciones concretas en las aulas y fuera de ellas.

Contrariamente, en el mundo actual existen instituciones educativas productoras de hegemonía, interesadas en evitar que otros pueblos y personas construyan su propia identidad, ya que con ello garantizan el éxito de sus programas de coloniaje y al mismo tiempo fomentan su vulnerabilidad (Mignolo, 2008). Para ello se diseñan proyectos que tienden a descalificar y ocultar los valores y creencias ajenas, principalmente de países del tercer mundo. Contra estas prácticas la educación tercermundista, la educación está obligada a desarrollar antídotos basados en conceptos descolonizadores (Dussel, 2006).

Por lo tanto, como existen instituciones educativas con políticas para favorecer la construcción social de la identidad hacia orientaciones concretas, existen también para destruir la del otro grupo, principalmente en aquellas que asumen como bandera el nacionalismo extremo. Usando la terminología de Foucault (1981) podemos afirmar que los antagonismos son expresión de la relación entre el ejercicio del poder y las manifestaciones de resistencia, por lo que la identidad se redefine permanentemente en medio de esta antinomia.

Comprender esta realidad es fundamental para fortalecer el papel de las ciencias sociales y humanísticas en los programas de formación de docentes, de manera que estos se preparen para poder identificar las formas sutiles que adoptan las configuraciones ideológicas y puedan participar de su análisis crítico en las aulas con el estudiantado.

La educación de la identidad es, a la vez, exploración, asimilación y reconocimiento del pasado. Esta es una condición necesaria para enseñar el "quién soy" y el de "dónde vengo", el "quienes somos" y el de "dónde venimos” y generar con ello el compromiso con la naturaleza, el legado histórico, la nación, la familia y el trabajo.

En esta misión, la educación juega un papel esencial de ruptura de la ignorancia, condición indispensable para auto-conocernos. La ignorancia puede ser una limitante para valorizar el significado del pasado y para proyectarse hacia el futuro.

Desde este enfoque histórico, la mirada al pasado que necesita la educación no debe significar un rescate, como muchas personas afirman, más bien de lo que debe tratarse es de mostrar la pertinencia de ese legado histórico en el presente. Todo en el pasado no es glorioso, por lo que incorporarlo implica reanalizar lo genuinamente humano en su ligazón con los errores de comportamientos y creencias de cada tradición: esto significa entrenar la capacidad de crítica y de elección, donde la educación es crucial.

Para ello, la educación no parte de cero, sino que existe un fundamento o capital de partida, sobre el que se forja el siempre inacabado proceso, que se asume como un camino de constante aproximación y 
separación de lo social. Es una dialéctica de relaciones donde la identidad se complementa con la diferencia, ambas se truecan en una correlación de causa y efecto participes de una interacción reciproca en la que invierten constantemente su papel. Los límites de una y otra son borrosos e inestables y se tornan difíciles al entendimiento.

Por lo tanto, si la educación participa de la construcción responsable de la identidad, abre puertas al reconocimiento de la diferencia, al espíritu del convivir con el otro ser, a la exploración y afirmación de la pluralidad de lo humano, con lo cual juega un papel importante en el rompimiento de la intolerancia fanática, que afecta las sociedades y muchas veces los escenarios escolares.

Plantearse desde la educación el tratamiento de la diferencia ha estado presente en las políticas instituidas en organismos internacionales, como la UNESCO (1994), y en las reformas educativas desarrolladas por muchos gobiernos, que la han asumido a partir de conceptos como educación inclusiva y educación multicultural.

La educación también actúa como un filtro donde se decide qué características identitarias estimular, qué resistencias vencer, cómo lograr el éxito. Las respuestas que estas interrogantes encuentran en las instituciones educativas son muy variadas, porque variados son los contextos y los intereses sociales.

Lo anterior hace de la educación una actividad que "nunca es neutral. ... Intenta favorecer un tipo de hombre frente a otros, un modelo de ciudadanía, de disposición laboral” (Savater, 1997, p. 65). Por tanto, se genera un espacio de toma de decisiones, que hasta ahora en Latinoamérica, lamentablemente como tendencia, nunca ha sido muy democrático y ha estado dominado por la influencia extranjera que, de manera intencionada, diseña políticas para desmontar la identidad del otro ser o grupo.

\section{LA EDUCACIÓN Y EL VALOR DE LA IGUALDAD EN LA CONSTRUCCióN SOCIAL DE LA IDENTIDAD}

En esta dialéctica del binomio identidad y diferencia, la igualdad es un valor y un derecho que adquiere un gran significado para la educación. Se trata de un proceso social donde es preciso asumir la igualdad en la diferencia como un valor imprescindible en la formación y construcción de la identidad.

El mundo arrastra desigualdades sociales de siglos, acrecentadas por las relaciones de intercambio nada equitativas que se manifiestan como diferencia entre las naciones y dentro de ellas, e incluso entre los individuos mismos. En estas circunstancias, el valor que significa el ejercicio de la igualdad debe convertirse en uno de los principales a fomentar por los sistemas educativos.

El valor de la igualdad es considerado una condición fundamental para edificar una identidad que exprese la verdadera condición humana. Está claro que los cambios estructurales juegan un papel fundamental en la superación de los grandes desequilibrios, pero la educación a través de la escuela puede hacer una labor nada despreciable, pues detrás de la inequidad generalmente existe ignorancia y carencia de un pensamiento liberador, aspectos que dependen en gran medida de procesos formativos:

La educación es la única forma que hay de liberar a los hombres del destino, es la antifatalidad por excelencia, lo que se opone a que el hijo del pobre tenga que ser siempre pobre; a que el hijo del ignorante tenga que ser siempre ignorante; la educación es la lucha contra la fatalidad. (Savater, 2000, p. 220)

La igualdad es un objetivo de lucha por el cual muchos individuos y pueblos han dedicado su vida, y se han convertido incluso en fundadores y símbolos de sus naciones. Esta ha constituido un tema del pensamiento social desde hace siglos, han sido construidas diversas ideologías donde cada época, cada lucha social añade nuevos argumentos y demandas en ese proceso del cual la educación no ha estado ajena.

Entonces, fomentar la igualdad en el proceso de construcción de la identidad se convierte en uno de los principales retos que tiene la educación, que, por supuesto, no significa solo el libre acceso de todas las personas a las instituciones educativas; aunque esto es importante, y en América Latína y otras partes del 
mundo se ha avanzado, es evidente que con ello no basta; las experiencias de los países que han ampliado la cobertura en cuanto al acceso muestran que no han podido superar las brechas cognitivas que se generan en los procesos de aprendizaje (Oviedo, Fiszbein y Sucre, 2015).

Se trata de la igualdad entre sujetos socialmente diferentes, por lo tanto, se necesita partir de organizar procesos de aprendizaje de contenidos básicos para todos; pero, al mismo tiempo, asegurar el desarrollo de una educación diferenciada, que implica atender, desde la institución, las necesidades cognitivas y educativas de cada estudiante.

La educación diferenciada es el mecanismo hasta ahora más efectivo para buscar un equilibrio en la formación de estudiantes socialmente diferentes, que provienen de familias diferentes, de comunidades diferentes, de culturas diferentes que interactúan desde el efecto de los procesos migratorios y con tiempos y ritmos de aprendizaje diferentes, de manera que quienes no tienen el apoyo necesario lo obtengan en la escuela.

Se trata de "salvar la unidad humana y salvar la diversidad humana. Desarrollar nuestras identidades concéntricas y plurales” (Morin 1999, p. 42). El fin no es negar la diferencia, sino crear condiciones y desarrollar acciones, para que la mayoría aproveche de manera eficaz y humanista su tránsito por la escuela y lograr, así, la reducción de la desigualdad de oportunidades. En definitiva la diferencia enriquece la identidad y viceversa.

Dentro de un sistema social, la ausencia de igualdad condiciona la pérdida de sentido de vida, en los sectores más desfavorecidos. Es difícil amar a la nación sintiéndose perjudicado por la diferencia, o preocuparse por el pasado heroico productor de significados en condiciones de pobreza extrema. Por otra parte, sin igualdad no hay espíritu de democracia ni libertad posible, valores imprescindibles para la verdadera emancipación.

Pero, si se quiere ser efectivo desde la educación, la búsqueda de la igualdad debe ir acompañada de la superación de la enseñanza tradicional de corte positivista y de la generación de una cultura de la innovación.

Superar la presencia, que aún tiene la educación tradicional de corte positivista, es parte de ese reto por la igualdad. Al absolutizar los valores cognitivos del conocimiento como verdad, coherencia y sistematicidad, la educación tradicional menosprecia el lugar de los sentimientos, soslaya el enfoque histórico en el aprendizaje de la ciencia, descontextualiza las teorías científicas que difunde y, con ello, genera un elitismo que a la larga monopoliza el conocimiento y termina reproduciendo la desigualdad: "Conforme el saber científico se ha transformado en un factor decisivo de la producción de bienestar, su distribución se ha vuelto más desigual" (UNESCO, 1999).

El cambio debe incorporar nuevas metodologías de enseñanza-aprendizaje. En un entorno dinámico y cambiante, configurado por la influencia de procesos globalizadores y por fuertes tendencias migratorias, la construcción social de la identidad debe fundamentarse en la aplicación de estrategias didácticas creativas, que no solo sean capaces de apreciar el pasado, sino que desarrollen capacidades para participar en situaciones nuevas y desconocidas y que, al mismo tiempo, participen de una educación con visión futurista, garante de la convivencia humana en relaciones de identidad y diferencia.

El otro componente importante en la construcción social de la identidad, donde la educación puede jugar un papel protagónico, consiste en crear bases para el desarrollo de una cultura de la innovación. Aunque algunos países han tenido avances, en realidad son los países desarrollados los que están marcando los procesos de innovación tecnológica (Núñez, 2008).

Los desequilibrios existentes en la distribución de la ciencia y la tecnología muestran la importancia de fundar relaciones de protagonismo en la producción de conocimiento, desde la educación, pues permite preparar a la ciudadanía para crear y asimilar tecnología y, con ello, autenticar un lugar para ese quiénes somos y de dónde venimos.

La cultura de la innovación para la educación representa la realización de acciones concretas que permitan desarrollar capacidades desde los sistemas educativos como: saber escuchar, estimular la generación de ideas, 
aprender a trabajar en equipos, aprender a cuestionar la manera de cómo se hacen las cosas y desarrollar percepción de riesgo en relación con la creación.

Por tanto, la cultura de la innovación es una clave para garantizar la soberanía de la identidad, es una manera de impedir que la diferencia se convierta en productora de relaciones enajenantes, a través de reproducir la inequidad económica y cognitiva ya existente. Es aquí donde un sistema educativo creativo, productor de ideas y formas nuevas se convierte en una verdadera contribución al acto de sentirse realizado con lo que somos.

Estas exigencias adoptan formas diversas en el discurso educativo actual, pues desde hace varias décadas se vienen difundiendo conceptos que, de manera cierta o en apariencia, significan un viraje en relación con el discurso tradicional: educación inclusiva, aprender a aprender, enseñanza por proyecto, educación para toda la vida, educación de calidad y otras iniciativas novedosas.

Estos términos promovidos por los organismos internacionales, por los ministerios de los gobiernos y por personal teórico de la pedagogía pueden enmascarar diversas ideologías. Se puede apreciar que la inclusión educativa es reconocida como derecho, condición indispensable de la igualdad, que participa de los sueños y aspiraciones de los pueblos; pero cuando nos preguntemos: ¿hasta dónde llega la inclusión?, ¿qué es lo que se va a aprender a aprender?, y, ¿para qué incluir?, entonces se descubren los matices que evidencian la presencia de intereses y perspectivas ideológicas.

Es necesario reconocer que este giro hacia formas más incluyentes y dinámicas en la educación puede ayudar a desmontar la educación tradicional, pero si ello no significa que el alumnado aprenda la esencia teórica de los conceptos de la ciencia y que pueda operar con el método científico, entonces seguirá creciendo la brecha cognitiva, que está en la base de las grandes desigualdades históricas y, por otra parte, tampoco se desarrollará una cultura de la innovación que sea capaz de contribuir al desarrollo de las regiones más atrasadas.

Es decir, si los conceptos de educación inclusiva, aprender a aprender, enseñanza por proyecto, se realizan a través de prácticas donde se opina de todo, no se llega a la esencia de nada y, al final, el alumnado no aprende los fundamentos teóricos de la ciencia, entonces estamos en presencia de la misma moneda tradicional con otra cara. El ideal de educación, supuestamente propuesto de inclusivo, termina siendo una forma abierta de exclusión.

Mientras que existan las grandes desigualdades económicas, políticas y cognitivas, la diferencia actuará como fuerza destructora de la identidad, manifestándose como racismo, discriminación y negación de oportunidades, al mismo tiempo que produce reacciones de intolerancia. Son realidades que tienen en su simiente problemas estructurales de siglos, pero donde la educación puede hacer una importante contribución para su superación, a partir de asumir prácticas de política educativa y estrategias didácticas que vayan al fondo y recuperen un concepto de igualdad realista.

Por último, el escenario actual de la construcción social de la identidad, plantea a la educación otros retos:

- Desarrollar el enfoque del género desde una perspectiva histórica, que permita explicar los orígenes de toda desigualdad y replantear la relación y el lugar de la mujer en la sociedad, así como el de cualquier orientación de sexual.

- Preparar a las colectividades para vivir interactuando con las heterogenias configuraciones de estructura comunitaria originadas por el desarrollo de los movimientos sociales.

- Desarrollar acciones educativas epistemológicamente fundamentadas para participar de un tema tan complejo como el de la identidad y la diversidad sexual.

- Desarrollar acciones de educación ambiental.

- Enfrentar la apatía escolar manifiesta, resultado de la influencia negativa de un mercado y una sociedad que centra su atención en el resultado y no en el esfuerzo y que muchas veces convierte en "exitosas" a personas de poco esfuerzo en los estudios. 
El abordaje de estas problemáticas, aunque no se explicitan en el presente texto, también es de interés para la educación, porque generan relaciones discriminatorias excluyentes y están asociadas a las transformaciones que los procesos libertarios actuales impulsan. Sin una educación de calidad el problema de la inequidad no se resuelve, pues esta tiene un papel formativo fundamental en la generación de sujetos socialmente protagonistas, dispuestos a involucrase en la trasformación de la sociedad.

\section{Conclusión}

En el proceso de construcción social de la identidad/diferencia, la educación de espíritu libertario debe jugar un papel básico, pues cuenta con potencialidades para desarrollar capacidades emancipadoras y de reinterpretar la riqueza espiritual contenida en las estructuras culturales de los pueblos.

Contribuir a la generación de relaciones de igualdad en función de la unidad como especie, superar la educación tradicional de carácter positivista y promover la formación de una cultura de la innovación y de producción de conocimientos son lineamientos que significan desafíos decisivos para los sistemas educativos actuales de los países en desarrollo.

Asumir la identidad en su relación con la diferencia exige a la educación enseñar a concertar, dialogar razonadamente, moderar comportamientos cuando sea necesario, aprender a reconciliar, a buscar consensos, tender puentes, democratizar el proceso de enseñanza aprendizaje, idear redes de asociación; en una palabra, promover el equilibrio de lo diverso.

\section{REFERENCIAS}

Adorno, T. W. (2005). Dialéctica negativa. Madrid: Ediciones Akal.

Ariño, A. (1997). Sociología de la cultura. Barcelona: Ariel.

Dussel, E. (2006). Filosofía de la cultura y la liberación. México: Universidad Autónoma de la Ciudad de México.

Engels. F. (1980). El papel del trabajo en la transformación del mono en hombre. En Obras Escogida, Marx y Engels (tomo II, pp. 33-39) . Moscú: Editorial Progreso.

Etzioni, A. (1999). La nueva regla de oro: Comunidad y moralidad en una sociedad democrática. Barcelona: Paidós.

Foucault, M. (1981). Un diálogo sobre el poder y otras conversaciones. Madrid: Tecnos.

Freire, P. (2002). Pedagogía de la esperanza. México DF: Siglo XXI.

Giddens, A. (1997). Modernidad e identidad del yo. El yo y la sociedad en la época moderna. Barcelona: Ediciones Península.

Hegel, G. (1982). Ciencia de la lógica. Buenos Aires, Argentina: Ediciones Solar.

Hegel, G. (2003). Fenomenología del espíritu. México: Fondo de Cultura Económica.

Lévi-Strauss, C. (1995). Antropología estructural. Barcelona: Paidós.

Lipovetsky, G. (2000). La era del vacío. Ensayos sobre el individualismo contemporáneo. Barcelona: Anagrama.

Maalouf, A. (1999). Identidades asesinas. Madrid, España: Alianza Editorial. Recuperado de http:// centroderecursos.cultura.pe/sites/default/files/rb/pdf/s_identidades_Asesinas.pdf

Malinowsky, B. (1984). Una teoría científica de la cultura. Madrid: Sarpe.

Marx, C. (1986). El capital (Tomo I). La Habana: Editorial de Ciencias Sociales.

Mignolo, W. D. (2008). La opción de-colonial: Desprendimiento y apertura. Un manifiesto y un caso. Revista Tabula Rasa, 8, 243-281. doi: https://doi.org/10.25058/20112742.331

Morin, E. (1999). Los siete saberes necesarios para la educación del futuro. París: UNESCO.

Núñez, J. (1999). La ciencia y la tecnología como procesos sociales. La Habana: Félix Varela. 
Núñez, J. (2008). Democratización de la ciencia y geopolítica del saber: ¿quién decide? ¿quién se beneficia? En J. Núñez y M. E. Masias. (Eds), Reflexiones sobre, ciencia, tecnología y sociedad (pp. 58-82) La Habana: Editorial Ciencias Médicas.

Oviedo, M., Fiszbein, A. y Sucre, F. (2015). Aprendizaje para todos: Un desafío pendiente para América Latina. Comisión para la educación de calidad para todos: Documento de antecedentes. Recuperado de http:// www.thedialogue.org/wp-content/uploads/2015/07/Aprendizaje-para-todos-web-2.pdf

Ricoeur, P. (2004). La memoria, la historia, el olvido. Buenos Aires: Fondo de Cultura Económica.

Savater, F. (1997). El valor de educar. Barcelona: Ariel.

Savater, F. (2000). La educación es el momento adecuado de la ética. ¿De qué sirve la ética para los jóvenes? Educare, 4 (11), 215 - 225. Recuperado de http://studylib.es/doc/6969022/la-educaci\%C3\%B3n-es-el-momentoadecuado-de-la-\%C3\%A9tica.\%C2\%BF-de-qu\%C3\%A9-...

Sousa, B. (2010). Descolonizar el saber, reinventar el poder. Montevideo: Ediciones Trilce.

Taylor, C. (2006). Fuentes del yo. La construcción de la identidad moderna. Barcelona: Piadós.

Tylor, E. B. (1975). La ciencia de la cultura. En J. S. Kahn (Comps.), El concepto de cultura: Textos fundamentales (pp. 29-46). Barcelona: Editorial Anagrama.

UNESCO. (1994). Conferencia mundial sobre necesidades educativas especiales: acceso y calidad (Informe final). Salamanca, España: Autor. Recuperado de http://unesdoc.unesco.org/images/0011/001107/110753so.pdf

UNESCO. (26 de junio al 1 de julio de 1999). Conferencia Mundial sobre la Ciencia. La ciencia para el Siglo XXI: Un nuevo compromiso. Budapest, Hungría: Autor. Recuperado de http://www.campus-oei.org/salacts

\section{BY-NC-ND}

